This is an electronic reprint of the original article. This reprint may differ from the original in pagination and typographic detail.

Author(s): Hämäläinen, Raija; De Wever, Bram; Malin, Antero; Cincinnato, Sebastiano

Title: $\quad$ Education and working life: VET adults' problem-solving skills in technology-rich environments

Year: $\quad 2015$

Version:

Please cite the original version:

Hämäläinen, R., De Wever, B., Malin, A., \& Cincinnato, S. (2015). Education and working life: VET adults' problem-solving skills in technology-rich environments. Computers and Education, 88(October), 38-47.

https://doi.org/10.1016/j.compedu.2015.04.013

All material supplied via JYX is protected by copyright and other intellectual property rights, and duplication or sale of all or part of any of the repository collections is not permitted, except that material may be duplicated by you for your research use or educational purposes in electronic or print form. You must obtain permission for any other use. Electronic or print copies may not be offered, whether for sale or otherwise to anyone who is not an authorised user. 


\title{
Education and working life: VET adults' problem-solving skills in technology-rich environments
}

\author{
Raija Hämäläinen ${ }^{a^{*},}$, Bram De Wever ${ }^{b}$, Antero Malin ${ }^{a}$ \& Sebastiano \\ Cincinnato $^{c}$
}

\footnotetext{
${ }^{\text {a }}$ University of Jyvaskyla, Finnish Institute for Educational Research, P.O.Box 35, 40014 Jyväskylä, Finland

b

Department of Educational Studies, Ghent University, Henri Dunantlaan 2, B-9000 Ghent, Belgium

${ }^{\mathbf{c}}$ Vrije Universiteit Brussel, Department of Educational Sciences, Pleinlaan 2, B-1050 Brussels, Belgium
}

*the contact details of the corresponding author; Finnish Institute for Educational Research, University of Jyväskylä, P.O.Box 35, 40014 Jyväskylä, Finland, raija.h.hamalainen@jyu.fi

\begin{abstract}
Postprint version of Hämäläinen, R., De Wever, B., Malin, A. \& Cincinnato, S. (2015).
Education and working life: VET adults' problem-solving skills in technology-rich environments. Computers \& Education, 88, 38-47. doi:10.1016/j.compedu.2015.04.013
\end{abstract}

\begin{abstract}
The rapidly-advancing technological landscape in the European workplace is challenging adults' problem-solving skills. Workers with vocational education and training need flexible abilities to solve problems in technology-rich work settings. This study builds on Finnish PIAAC data to understand adults' $(N=4503)$ skills for solving problems in technology-rich environments. The results indicate the critical issue that more than two thirds of adults with vocational education and training have weak skills or lack the skills in solving problems in technology-rich environments and that more than one fifth of these adults are at risk. Furthermore, this study indicates that the likelihood of having fragile problem-solving skills is six times higher for adults with vocational education and training than for adults with at least upper secondary qualification. Since the need for problem-solving in technologyrich environments is likely to increase in the future, this study also identifies the indicators for problem-solving skills differences. The models predicting problem-solving skills on the basis of theoretical assumptions as well as empirical support are presented. Our results indicate that adults' lower performance does not seem to be associated with the vocational education and training educational system itself, but is mostly due to age, education in years, occupation, and gender, as well as work-related and everyday life factors. In practice, the models help to develop new approaches to enable novel problem-solving skills in technology-rich environments based on the current European workplace needs.
\end{abstract}

Keywords: vocational education and training (VET); problem-solving; technology-rich environments; large-scale assessment - PIAAC; work-based and everyday life learning 


\section{Introduction}

The European workplace is changing rapidly. For example the industrial sector, where factories are transitioning from mass-production technology to more flexible production methods, e.g. with the aid of robotic techniques, is going through a radical process of structural change (Goos, 2013). Companies that are facing economic hardships are innovating their production processes, often resulting in large-scale changes in working practices (Jaimovich \& Siu, 2012). These organisational changes result in changes in adults' occupations (Attwell, 1997). The current trend at workplaces seems to be that technologies are taking over routine tasks, leaving workers to accomplish non-routine tasks (Goos, 2013). This structural change involves millions of adults with vocational education and training (VET). In Finland alone, more than 100,000 jobs have disappeared from the industrial sector over the past ten years (Taloussanomat, 4.1.2014). In line with this, the largest decline in occupations at the European level concerns typical VET occupations, such as craft-workers and machine operators (Goos, Manning, \& Salomons, 2009). Moreover, when studying the susceptibility of jobs to computerisation, Frey and Osborne (2013) mentioned that about 47 percent of jobs in the US are at risk of disappearing within the next 20 years.

The technological landscape influences society and its necessities regarding adults' skills. According to scholars like Frey and Osborne (2013), Attwell (1997), Levy (2010), and Stenstöm and Tynjälä (2009), the key challenge in addressing evolutions for working life involves developing vocational skills and professional expertise that match the changing needs of society. As a direct result of current technological advancements, job descriptions of adults with VET change (Maclean \& Wilson, 2009; Tuomi-Gröhn \& Engeström, 2003). VET workers are facing two major challenges: (1) a technology challenge, as there is a snowballing need for continuous professional development to deal with the evolving character of technology (Herder Koesling, Olmedilla, Hummel, \& Schoonenboom, 2006), and (2) a problem-solving challenge, as there is crucial extension of skills needed in problem-solving within these new technology-rich settings (Brand-Gruwel \& Stadtler, 2011). In line with these challenges, it is widely agreed that problem-solving in technology-rich environments (TRE) is one of the most important skills for working life (e.g. Goos, 2013). At the same time, it is not yet clear what kind of proficiency adults with VET currently have with regard to problem-solving skills in TRE and what kind of factors contribute to successful adults' skills.

To guide research, policy, and practise, empirical evidence of adults' skills and competencies is needed. The data from the Programme for the International Assessment of Adult Competencies (PIAAC) from the Organisation for Economic Co-operation and Development (OECD) comprise the most comprehensive source of information about adult skills ever undertaken (OECD, 2013a). PIAAC provides important insights into adults' literacy, numeracy and problem-solving in TRE skills. In particular, PIAAC can be used to identify and predict current and emerging needs in problem-solving skills in TRE. Additionally, PIAAC information can provide further comprehension of the relationship between education and the world of work. As such, it encourages us to develop new ways of increasing learning throughout adults' working careers.

\section{Aims}

The aim of this study is to identify and discuss the level of problem-solving skills in TRE of adults with VET. More specifically, our aim is to reveal what basic skills 16-65 year-old adults with VET and adults with other educational backgrounds have regarding problem-solving in TRE. Considering the changing needs of European workplaces, especially with relation to problem-solving skills, the first aim is to identify adults with VET that can be considered "at-risk" (i.e. having very limited 
problem-solving skills), "weak performers", "moderate performers" and "strong performers". The first two research questions are:

RQ1: What is the level and distribution of problem-solving skills in TRE for adults with VET?

RQ2: How is the level and distribution of problem-solving skills in TRE of VET-adults related to adults with other educational backgrounds?

Having identified the "at-risk", the "weak performers" and the stronger performing adults, the second aim is to explore which factors are highly associated with being either at-risk or more proficient as a worker and whether the differences in problem-solving between VET adults and adults with other educational backgrounds actually depend on the VET itself. The respective research questions are:

RQ3: What factors explain the variation in problem-solving skills in TRE?

RQ4: What are the differences in problem-solving skills in TRE between adults with other educational backgrounds and VET adults in predefined age groups, before and after controlling the effects of statistically significant background factors?

\section{Methods}

\subsection{Material: PIAAC data}

PIAAC data were used in this study. PIAAC is a large-scale, ongoing programme for monitoring performance in literacy, numeracy and problem-solving in TRE amongst adults. In total, 24 countries participated in the first round. The objective of the PIAAC was to determine whether adults' basic skills were at a sufficient level to respond to the unpredictable needs of the future. Direct measures of skills were developed to accomplish this feat (OECD, 2013b).

In this article, we focus on the assessment of problem-solving (for definitions of problem-solving, see e.g., Brand-Gruwel \& Stadtler, 2011; Levy, 2010) in TRE. In PIAAC, problem-solving in technologyrich environments is defined as follows:

"Problem solving in technology-rich environments involves using digital technology, communication tools and networks to acquire and evaluate information, communicate with others and perform practical tasks. The first PIAAC problem solving survey will focus on the abilities to solve problems for personal, work and civic purposes by setting up appropriate goals and plans, accessing and making use of information through computers and computer networks". (OECD, 2012, p. 47)

In assessing problem-solving in TRE, the aim was to evaluate adults' ability to use technology for accomplishing complex problem-solving tasks. The participants solved tasks using various sources of information on a laptop computer, such as an Internet browser, e-mail, or word processing programme. Furthermore, to allow researchers to understand what kinds of skills participants used and how actively, participants answered questionnaires about their skills and their backgrounds. The background questionnaire, the tasks and the assessment framework were designed by international expert groups (see OECD, 2012).

Proficiency in problem-solving is measured on a scale ranging from 0 to 500. Additionally, proficiency scores are grouped into four proficiency levels based on the knowledge and skills required to complete the tasks within those levels (see OECD, 2013b). These predefined proficiency levels include: (1) below Level 1, or 'at-risk performers': proficiency scores ranging from 0 to 240 points, (2) Level 1, or 'weak performers': scores ranging from 241 to 290 points, (3) Level 2, or 'moderate performers': scores ranging from 291 to 340 points, and (4) Level 3, or 'strong performers': scores ranging from 341 to 500 points. A detailed description of the PIAAC proficiency scales and levels as well as the knowledge and skills required to complete the tasks within those levels is provided in the 
PIAAC Technical Report (OECD, 2013b; chapter 21). Additionally, in line with the study guidelines (see OECD, 2013b), the sample encompasses a "not classified" group that, for example, failed the ICT core test, had no computer experience or "opted out" of taking computer-based assessments. For these participants, the problem-solving proficiency scores are not available and they could not be included in the statistical analyses.

In Finland, a total of 5464 people between the ages of 16 and 65 were involved (weighted response rate: 66\%; sample size: 8099). However, data for 4503 adults concerning their problem-solving skills in TRE were collected (2252 males, 2251 females).

\subsection{Data analysis ${ }^{1}$}

\subsubsection{Identifying the level of problem-solving skills and exploring the differences between VET and other adults' problem-solving skills (RQ1\&2)}

As a first step of the analysis, the level and distribution of problem-solving skills for all participants were calculated. Next, VET and other adults were classified based on the scores they achieved on the problem-solving test. The differences and similarities in the relationship between participants' background (education and age) and the scores of the problem-solving test were explored. Finally, adults of differing age groups and educational backgrounds were compared. We performed a multinomial logit regression to estimate the likelihood of achieving a certain proficiency level based on educational background. In particular, we modelled the likelihood of achieving an at-risk or weak proficiency level as compared to a moderate or strong proficiency level (which we combined and used as the reference category). Furthermore, vocationally trained adults and adults with no more than a lower secondary education were compared to adults with at least an upper secondary education (i.e., the reference category).

\subsubsection{Building a model to identify background factors associated with problem-solving skills in TRE (RQ3)}

We investigated problem-solving skills and competencies in TRE from the perspective of the sociallysituated nature of learning. Our starting point was that the knowledge and skills of adults are always related to their lives, their personal life history and their real-life problems; therefore, we need to try to understand and link these factors together to create meaningful and relevant interpretations. Therefore, the model aims to identify factors explaining the variations in adults' problem-solving skills based on theoretical assumptions as well as empirical support.

Theoretical assumptions: We used previous research of adults' competencies and skills as a starting point for analysing the PIAAC data. In short, previous studies of adults' competencies and skills lie at the crossroads of the research on (1) workplace learning, which highlights learning taking place at work, through work and for work (e.g., Tynjälä, 2013), (2) school-based learning, which is grounded in formal education, such as vocational education (Billet, 2008), higher education (Teichler, 2007) and (3) internships between schools and workplaces (Virolainen \& Stenström, 2013). Additionally, the rising trend seems to be that learning that occurs in everyday life is increasingly taken into account in research, e.g., perspectives related to everyday learning, such as life-long learning and informal learning (Loveder, 2011; Schulz \& Stamov Roßnagel, 2010). Therefore, we conducted a thematic analysis (Braun \& Clarke, 2006) of the PIAAC variables (see OECD, 2013b, for the description of the 1600 variables). As a result of the thematic analysis, we identified three clusters of variables for our

\footnotetext{
${ }^{1}$ The statistical analyses were carried out taking the complex survey design into account, i.e., calculating proficiency scores across ten plausible values and using Jack-knife replication for variance estimation (for more details, see OECD, 2013b; chapters 14 \& 15).
} 
model (see Table 1): (1) socio-demographic factors, (2) work-related learning variables, and (3) variables related to everyday learning. Next, participants' answers on the background questionnaires (e.g., what kinds of skills participants used and how actively) were capitalised on to generate information about problem-solving skills. After reading and investigating the PIAAC data, 108 variables were selected to be used as indicators for the three clusters of variables.

$* * * * * * * * * * *$

Insert Table 1 about here: Overview of the three clusters of explanatory variables and the outcome variable

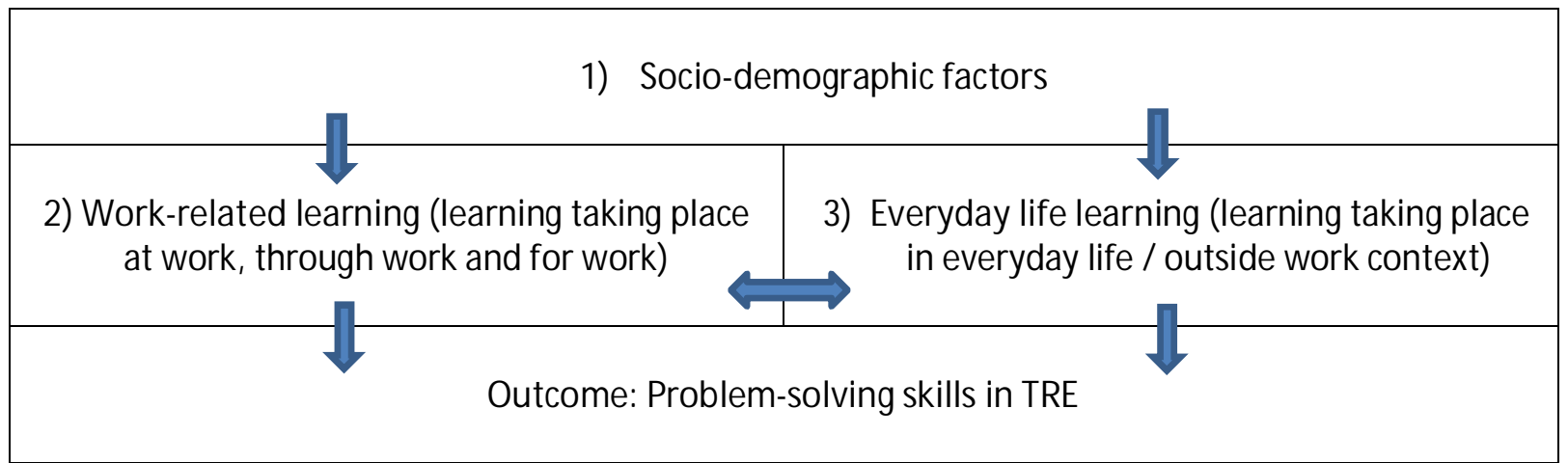

$* * * * * * * * * * * *$

In the first cluster of variables, we focussed on the socio-demographic factors that shape adults' life experiences (including background variables such as age and gender).

The second cluster of variables is associated with work-related learning experiences (e.g., Eraut, 2004; Fuller \& Unwin, 2004; Billet, 2008; Tynjälä, 2013). This cluster comprises (1) general skills used at work and (2) more specific ICT skills used at work. We expect that general and specific ICT skills used at workplaces will have a positive influence on problem-solving skills in TRE. For example, by performing certain work tasks, adults will have better skills (Billet, 2008). Additionally, this cluster focusses on (3) learning through work, as there is always a certain amount of learning going on at work, depending on the type of job performed (Tynjälä, 2013). Finally, this cluster also consists of the (4) formal and non-formal educational activities that are related to adults' working-life needs. It is expected that participating in formal or externally hosted non-formal training activities is beneficial for having better problem-solving skills in TRE.

The third cluster of variables includes variables focussing on learning in everyday life and was specifically added because these variables have often been neglected when investigating VET adults' skills. In this study, we wanted to make a shift towards developing a new understanding of how everyday life learning is related to adults' skills in problem-solving in TRE (see, e.g., Schulz \& Robinagel, 2010; Hager, 2001). Therefore, the third cluster focusses on everyday life learning experiences. Thus, in our model, we included variables related to the learning taking place in everyday life (ICT skill use in everyday life, and formal and non-formal education for non-workrelated reasons). We aim to explore how these variables influence how both specific and generic skills related to problem-solving in TRE are enhanced and maintained. Furthermore, we aim to find indicators in the data related to what kind of everyday life learning can be beneficial in answering the needs of the current European workplace and adults' skills regarding the transformative development of problem-solving in TRE. 
Empirical support: In the second phase of building the model, we identified the most important background factors associated with problem-solving skills in the three clusters of variables. Next, only statistically significant background factors were selected for detailed investigation, so, in contrast to the first phase, the second phase was more data-driven. As our aim was to find new ways to identify successful links related to adults' real-life problem-solving in TRE, the statistical models simultaneously included factors associated with problem-solving proficiency. In the first model (Model 1 in the results section, Table 4), we used all the statistically significant socio-demographic factors (i.e., cluster 1) as a set of predictors. In the second model (Model 2), in addition to the sociodemographic factors, we included statistically significant work-related factors (i.e., cluster 1+2) as a set of predictor variables. In the third model (Model 3), we used statistically significant everyday life learning factors as a set of predictors instead of work-related factors (i.e., cluster 1+3). Finally, in the fourth model (Model 4), we used statistically significant work and everyday learning factors as predictor variables, including the socio-demographic factors in the model as well (i.e., cluster $1+2+3$ ). (The results in Table 4 give a complete overview of the variables entered in each model). The statistical method used in the analyses is a multiple linear regression model (see, e.g., Peers 1996; Aczel, Sounderpandian, Saravanan \& Joshi, 2012) with dummy-coded categorical variables.

\subsubsection{Exploring the differences between adults with VET and other educational backgrounds (RQ4)}

Having identified the variables explaining variations in problem-solving skills in TRE, we focussed on the extent to which the differences in problem-solving between VET adults and adults with other educational backgrounds actually depend upon having followed VET or the factors associated with problem-solving in the statistical models 1 to 4 . Therefore, we first explored whether the background factors were identically related to the problem-solving skills of VET adults and adults with other educational backgrounds by testing if there are interactions between background factors and VET groups. Preliminary analysis using only plausible value 1 detected no significant interactions.

Next, we investigated how the differences in problem-solving skills in TRE between the four adult groups (i.e., VET versus other educational backgrounds, and $\geq 40$ versus $<40$ years of age) were affected when controlling for the background factors in models 1 to 4 . To do so, we examined to what extent both the size and significance of parameters in the baseline model - i.e., Model 0 with only the adult groups as predictors of problem-solving proficiency - shifted as a result of controlling sociodemographic, work-related and everyday life learning factors in Models 1 to 4.

\section{Results}

\subsection{RQ1: VET adults' problem-solving skills in technology-rich environments}

Table 2 shows that roughly one in five (22.0\%) adults with vocational education are at-risk performers in problem-solving. Additionally, four in ten (44.4\%) are weak performers. Roughly one third (29.8\%) perform moderately, and only four in a hundred (3.8\%) perform strongly. These figures indicate that, among adults with vocational education, there is a tendency to have low problemsolving skills. This tendency for lower performance is even more pronounced when comparing the VET group with adults with other educational backgrounds, especially when comparing them to adults with at least upper secondary education. In fact, the latter strongly outperform the vocationally trained adults. Slightly more than one third (36.1\%) of these adults are classified as "at risk" (6.9\%) or "weak" (29.2\%). Furthermore, nearly half (48.5\%) perform moderately and $15.5 \%$ perform strongly. Further controls for age indicate that the outperformance of upper secondary graduates compared to 
vocationally trained adults is even more pronounced for younger adults (16-39 years) than older adults (40-65 years).

$* * * * * * * * * * * *$

\section{Insert Table 2 about here:}

Distribution of proficiency in problem-solving in TRE by educational background (in \%): population, 16-39year olds, and 40-65-year olds

\begin{tabular}{|c|c|c|c|c|c|c|c|c|c|}
\hline & \multicolumn{3}{|c|}{ POPULATION } & \multicolumn{3}{|c|}{ 16-39 YEARS } & \multicolumn{3}{|c|}{ 40-65 YEARS } \\
\hline & \multirow[t]{2}{*}{ VET } & \multicolumn{2}{|c|}{ NON-VET } & \multirow[t]{2}{*}{ VET } & \multicolumn{2}{|c|}{ NON-VET } & \multirow[t]{2}{*}{ VET } & \multicolumn{2}{|c|}{ NON-VET } \\
\hline & & $\begin{array}{l}\text { Low } \\
\text { Sec. }\end{array}$ & $\begin{array}{l}\text { Up. } \\
\text { Sec. }\end{array}$ & & $\begin{array}{l}\text { Low } \\
\text { Sec. }\end{array}$ & $\begin{array}{l}\text { Up. } \\
\text { Sec. }\end{array}$ & & $\begin{array}{l}\text { Low } \\
\text { Sec. }\end{array}$ & $\begin{array}{l}\text { Up. } \\
\text { Sec. }\end{array}$ \\
\hline At risk & 22.0 & 20.1 & 6.9 & 8.6 & 6.0 & 1.6 & 34.1 & 49.4 & 12.4 \\
\hline Weak & 44.4 & 39.7 & 29.2 & 40.0 & 39.0 & 17.1 & 48.4 & 41.1 & 41.6 \\
\hline Moderate & 29.8 & 35.4 & 48.5 & 44.7 & 48.1 & 56.6 & 16.4 & 8.8 & 40.0 \\
\hline Strong & 3.8 & 4.9 & 15.5 & 6.7 & 6.9 & 24.6 & 1.1 & 0.8 & 6.0 \\
\hline Total & 100 & $\overline{100}$ & 100 & $\overline{100}$ & $\overline{100}$ & 100 & 100 & 100 & 100 \\
\hline $\mathbf{N}$ & 1307 & 640 & 2556 & 605 & 438 & 1258 & 702 & 202 & 1298 \\
\hline
\end{tabular}

Note: Low Sec. =lower secondary or less (ISCED 1, 2, 3C (short)); Up. Sec. =upper secondary or more (ISCED 3 A-B-C(long), 5 A-B, 6).

${ }^{a}$ These percentages should be interpreted with care since there is an overrepresentation of "not classified" 40-65-year olds with not more than lower secondary education (see Table A1).

$* * * * * * * * * * * *$

Interestingly, adults with no more than lower secondary education seem to slightly outperform vocationally trained adults. On the one hand, the former are less likely to perform on the lower proficiency levels, with one out of five (20.1\%) being at risk and four out of ten (39.7\%) being weak performers. At the same time, they are more likely to achieve higher proficiency levels, with one third (35.4\%) being moderate and one out of twenty (4.9\%) being strong performers. Further controls for age indicate that younger adults are responsible for the better performance of adults with no more than secondary education. However, it should be considered that the majority of this young adult population with no more than lower secondary education consists of adults who are still in (nonvocational) education (73.4\%). This possibly explains why younger adults with no more than lower secondary education appear to perform slightly better than younger vocationally trained adults.

\subsection{RQ2: The differences between VET and other adults' problem-solving skills}

Table 3 presents the main variations of different adults' (with regard to age and educational background) problem-solving proficiency. The odds of being an at-risk performer as opposed to a moderate or strong performer increases by a factor of six for vocationally trained adults compared to adults with at least upper secondary education. Likewise, vocationally trained adults are three times more likely to be weak performers. These results confirm what was already suggested under 4.1. above, namely that vocational education is negatively associated with problem-solving proficiency. Breaking down the results by age cohort reveals that younger, vocationally trained adults are 8.5 times as likely to be at risk and 3.7 times more likely to have a weak proficiency level. So compared to the VET population as a whole, younger VET adults are more likely to be at risk or weak performers although this difference is not statistically significant(respectively $\mathrm{p}=.34$ and $\mathrm{p}=.09$ ). Having at most lower secondary education shows the same negative association with proficiency in problem-solving 
as vocational education. This finding, however, should be treated carefully. As indicated above, the majority of the younger adults within this population are still in (general) education. Since this level of education generally prepares individuals for higher skills proficiency, this might also explain why adults with no more than lower secondary education are less likely to be at-risk or weak performers in problem-solving.

$* * * * * * * * * * *$

Insert Table 3 about here: Likelihood of proficiency in problem-solving in TRE by educational background (parameter estimates and odds ratios): population, 16-39-year olds, and 40-65-year olds

\begin{tabular}{rrrrrrrr}
\hline & \multicolumn{3}{c}{ POPULATION } & \multicolumn{2}{c}{ 16-39 YEARS } & \multicolumn{2}{c}{ 40-65 YEARS } \\
\hline B & SE $\begin{array}{l}\text { Odds } \\
\text { ratio }\end{array}$ & b & SE & $\begin{array}{l}\text { Odds } \\
\text { ratio }\end{array}$ & b & SE $\begin{array}{l}\text { Odds } \\
\text { ratio }\end{array}$ \\
\hline
\end{tabular}

At risk vs. moderate or strong performer

\begin{tabular}{lrrrrrrrrl}
\hline Intercept (Up. Sec.) & $-2.22 * * *$ & 0.08 & & $-3.92 * * *$ & 0.25 & & $-1.31 * * *$ & 0.10 & \\
VET vs. Up. Sec. & $1.80 * * *$ & 0.13 & 6.06 & $2.14 * * *$ & 0.32 & 8.47 & $1.98 * * *$ & 0.15 & $7.25^{a}$ \\
Low Sec. vs. Up. Sec. & $1.53 * * *$ & 0.16 & 4.61 & $1.70 * * *$ & 0.40 & 5.46 & $2.98 * * *$ & 0.35 & $19.77^{a}$
\end{tabular}

Weak vs. moderate or strong performer

\begin{tabular}{|c|c|c|c|c|c|c|c|c|c|}
\hline Intercept (Up. Sec.) & $-0.78 * * *$ & 0.05 & & $-1.56 * * *$ & 0.09 & & -0.10 & 0.06 & \\
\hline VET vs. Up. Sec. & $1.06^{* * *}$ & 0.08 & 2.90 & $1.31^{* * *}$ & 0.12 & 3.71 & $1.12^{* * *}$ & 0.13 & $3.06^{\mathrm{a}}$ \\
\hline Low Sec. vs. Up. Sec. & $0.77 * * *$ & 0.12 & 2.16 & $1.21 * * *$ & 0.15 & 3.37 & $1.58 * * *$ & 0.40 & $4.84^{\mathrm{a}}$ \\
\hline $\mathbf{N}$ & 4503 & & & 2301 & & & 2202 & & \\
\hline $\mathbf{R}^{2}$ (Nagelkerke) & 0.10 & & & 0.12 & & & 0.16 & & \\
\hline \multicolumn{10}{|c|}{$\begin{array}{l}\text { Note: * } p<.05, * * p<.01, * * * p<.001 . \text { Low Sec. }=\text { lower secondary or less (ISCED 1, 2, 3C (short)); } \\
\text { Up. Sec. =upper secondary or more (ISCED } 3 \text { A-B-C(long), } 5 \text { A-B, 6). } \\
\text { a Parameter estimates and standard errors might be biased due to an overrepresentation of "not } \\
\text { classified" 40-65-year olds with not more than lower secondary education (see Table A1). }\end{array}$} \\
\hline
\end{tabular}

$* * * * * * * * * * * *$

The results also indicate that the likelihood of being an at-risk performer in problem-solving tends to be greater for younger than for older adults. However, these results should be treated with caution. The majority of older adults were unable to perform the problem-solving test (i.e. "not classified") (see Table A1). Hence, parameter estimates might be biased.

In summary, vocationally trained adults show a higher propensity of being at-risk and weak performers and a lower propensity of being strong performers.

\subsection{RQ3: The factors explaining the variation in problem-solving in TRE}

In Table 4, four statistical models explaining problem-solving variation are presented. In practice, the table shows which of the factors were statistically significant predictors of problem-solving abilities in TRE. In Model 1, focusing on the relationship between socio-demographic factors and problemsolving skills, the explanatory variables are age, education in years, occupation and gender. The association between age and problem-solving was not linear, and the quadratic effect was needed. The association between age and problem-solving is presented Figure 1. Again, in general, younger persons were more proficient than older ones. Actually, the gap between the old and the young was even larger than the difference between two proficiency levels (50 points). With regard to the 
association between years of education and skills, one more year in education is associated with a 4point increase in problem-solving proficiency. Among four occupational categories, the semi-skilled blue collar occupations (reference category) have the lowest performance level. Adults working in skilled occupations score on average 19 points higher and those in semi-skilled white collar occupations 10 points higher than the reference group. In addition, males' proficiency score is almost 8 points higher than females'. Together, the socio-demographic variables explained $37 \%$ of the variance in problem-solving skills. In sum, these four socio-demographic factors significantly predicted problem-solving performance.

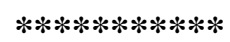

Insert Table 4 about here: Regression models of problem-solving in TRE on socio-demographic factors, work-related learning and everyday life learning 


\begin{tabular}{|c|c|c|c|c|c|c|c|c|c|c|c|c|}
\hline & \multicolumn{3}{|c|}{ Model 1} & \multicolumn{3}{|c|}{ Model 2} & \multicolumn{3}{|c|}{ Model 3} & \multicolumn{3}{|c|}{ Model 4} \\
\hline & $\mathrm{b}$ & $\mathrm{se}(\mathrm{b})$ & $\mathrm{p}$ & b & $\mathrm{se}(\mathrm{b})$ & $\mathrm{p}$ & $\mathrm{b}$ & $\mathrm{se}(\mathrm{b})$ & $\mathrm{p}$ & $\mathrm{b}$ & $\mathrm{se}(\mathrm{b})$ & $\mathrm{p}$ \\
\hline Intercept & 226.6 & 4.88 & & 231.8 & 7.34 & & 211.0 & 5.68 & & 224.9 & 7.38 & \\
\hline \multicolumn{13}{|l|}{ Socio-demographic factors } \\
\hline \multicolumn{13}{|l|}{ Age (centered at 40 years) } \\
\hline Linear effect & -1.61 & 0.05 & $<0.001$ & -1.70 & 0.08 & $<0.001$ & -1.380 & 0.05 & $<0.001$ & -1.511 & 0.08 & $<0.001$ \\
\hline Quadratic effect & -0.02 & 0.00 & $<0.001$ & -0.01 & 0.01 & 0.053 & -0.023 & 0.00 & $<0.001$ & -0.017 & 0.01 & 0.009 \\
\hline \multicolumn{13}{|l|}{ Education } \\
\hline Highest level of education obtained in years & 3.9 & 0.35 & $<0.001$ & 2.7 & 0.39 & $<0.001$ & 3.0 & 0.34 & $<0.001$ & 2.3 & 0.39 & $<0.001$ \\
\hline \multicolumn{13}{|l|}{ Occupation } \\
\hline Skilled occupations & 19.3 & 2.13 & $<0.001$ & 13.3 & 2.82 & $<0.001$ & 15.8 & 1.96 & $<0.001$ & 12.7 & 2.76 & $<0.001$ \\
\hline Semi-skilled white-collar occupations & 9.8 & 2.01 & $<0.001$ & 8.3 & 2.61 & $<0.001$ & 7.9 & 1.86 & $<0.001$ & 8.5 & 2.54 & 0.001 \\
\hline Elementary occupations & 4.9 & 2.58 & 0.055 & 4.8 & 4.23 & 0.254 & 4.6 & 2.49 & 0.069 & 3.1 & 4.21 & 0.456 \\
\hline Semi-skilled blue-collar occupations (ref.) & 0 & & & 0 & & & 0 & & & 0 & & \\
\hline \multicolumn{13}{|l|}{ Gender } \\
\hline Male & 7.5 & 1.26 & $<0.001$ & 4.8 & 1.58 & 0.002 & 4.6 & 1.28 & $<0.001$ & 3.7 & 1.57 & 0.017 \\
\hline Female (ref.) & 0 & & & 0 & & & 0 & & & 0 & & \\
\hline \multicolumn{13}{|l|}{ Work-related learning } \\
\hline \multicolumn{13}{|l|}{ Use of numeracy skills at work } \\
\hline All zero response (ref.) & & & & 0 & & & & & & & & \\
\hline Most passive $20 \%$ & & & & 3.3 & 4.67 & 0.480 & & & & & & n.s. \\
\hline More than $20 \%$ to $40 \%$ & & & & 9.4 & 4.34 & 0.030 & & & & & & n.s. \\
\hline More than $40 \%$ to $60 \%$ & & & & 10.6 & 4.62 & 0.022 & & & & & & n.s. \\
\hline More than $60 \%$ to $80 \%$ & & & & 11.5 & 4.46 & 0.011 & & & & & & n.s. \\
\hline Most active $80 \%$ to $100 \%$ & & & & 12.2 & 4.70 & 0.009 & & & & & & n.s. \\
\hline \multicolumn{13}{|l|}{ Use of ICT skills at work } \\
\hline All zero response (ref.) & & & & 0 & & & & & & 0 & & \\
\hline Most passive $20 \%$ & & & & 3.4 & 4.55 & 0.455 & & & & 1.8 & 4.65 & 0.707 \\
\hline More than $20 \%$ to $40 \%$ & & & & 6.4 & 4.70 & 0.173 & & & & 4.8 & 4.49 & 0.286 \\
\hline More than $40 \%$ to $60 \%$ & & & & 15.4 & 4.76 & 0.001 & & & & 12.1 & 4.40 & 0.005 \\
\hline More than $60 \%$ to $80 \%$ & & & & 19.9 & 4.85 & $<0.001$ & & & & 16.3 & 4.62 & $<0.001$ \\
\hline Most active $80 \%$ to $100 \%$ & & & & 20.6 & 5.22 & $<0.001$ & & & & 15.8 & 5.24 & 0.003 \\
\hline \multicolumn{13}{|l|}{ Learning at work } \\
\hline All zero response and most passive $20 \%$ (ref.) & & & & 0 & & & & & & 0 & & \\
\hline More than $20 \%$ to $40 \%$ & & & & -3.3 & 2.85 & 0.245 & & & & 5.5 & 2.63 & 0.038 \\
\hline More than $40 \%$ to $60 \%$ & & & & -4.6 & 2.65 & 0.080 & & & & 1.5 & 2.20 & 0.499 \\
\hline More than $60 \%$ to $80 \%$ & & & & -6.4 & 2.85 & 0.023 & & & & -2.3 & 1.88 & 0.223 \\
\hline Most active $80 \%$ to $100 \%$ & & & & -8.7 & 3.27 & 0.008 & & & & -4.8 & 2.42 & 0.048 \\
\hline \begin{tabular}{|c|} 
Everyday life learning \\
\end{tabular} & & & & & & & & & & & & \\
\hline Use of numeracy skills in everyday life & & & & & & & & & & & & \\
\hline All zero response and most passive $20 \%$ (ref.) & & & & & & & 0 & & & 0 & & \\
\hline More than $20 \%$ to $40 \%$ & & & & & & & 2.9 & 2.92 & 0.315 & 1.2 & 3.68 & 0.740 \\
\hline More than $40 \%$ to $60 \%$ & & & & & & & 5.3 & 2.84 & 0.063 & 4.1 & 3.66 & 0.270 \\
\hline More than $60 \%$ to $80 \%$ & & & & & & & 8.8 & 2.81 & 0.002 & 7.7 & 3.73 & 0.041 \\
\hline Most active $80 \%$ to $100 \%$ & & & & & & & 12.0 & 3.02 & $<0.001$ & 10.2 & 3.82 & 0.008 \\
\hline Use of ICT skills in everyday life & & & & & & & & & & & & \\
\hline All zero response and most passive $20 \%$ (ref.) & & & & & & & 0 & & & 0 & & \\
\hline More than $20 \%$ to $40 \%$ & & & & & & & 4.8 & 2.23 & 0.032 & 2.8 & 2.73 & 0.298 \\
\hline More than $40 \%$ to $60 \%$ & & & & & & & 9.4 & 2.38 & $<0.001$ & 7.0 & 2.90 & 0.015 \\
\hline More than $60 \%$ to $80 \%$ & & & & & & & 14.4 & 2.58 & $<0.001$ & 10.0 & 2.94 & 0.001 \\
\hline Most active $80 \%$ to $100 \%$ & & & & & & & 19.5 & 3.04 & $<0.001$ & 14.6 & 3.60 & 0.000 \\
\hline Use of reading skills in everyday life & & & & & & & & & & & & \\
\hline All zero response and most passive $20 \%$ (ref.) & & & & & & & 0 & & & 0 & & \\
\hline More than $20 \%$ to $40 \%$ & & & & & & & 11.7 & 3.20 & $<0.001$ & 5.8 & 4.58 & 0.202 \\
\hline More than $40 \%$ to $60 \%$ & & & & & & & 14.6 & 3.41 & $<0.001$ & 9.2 & 4.70 & 0.049 \\
\hline More than $60 \%$ to $80 \%$ & & & & & & & 16.9 & 3.54 & $<0.001$ & 10.5 & 4.92 & 0.032 \\
\hline Most active $80 \%$ to $100 \%$ & & & & & & & 16.4 & 3.71 & $<0.001$ & 9.5 & 4.96 & 0.055 \\
\hline R squared (adjusted) & 0.368 & & & 0.376 & & & 0.413 & & & 0.390 & & \\
\hline Unweighted $\mathrm{n}$ & 4145 & & & 2782 & & & 4072 & & & 2734 & & \\
\hline
\end{tabular}

Note: statistically significant $p$-values in bold; $n$.s. $=$ not significant 
Insert Figure 1 about here: Association between problem-solving in TRE and age

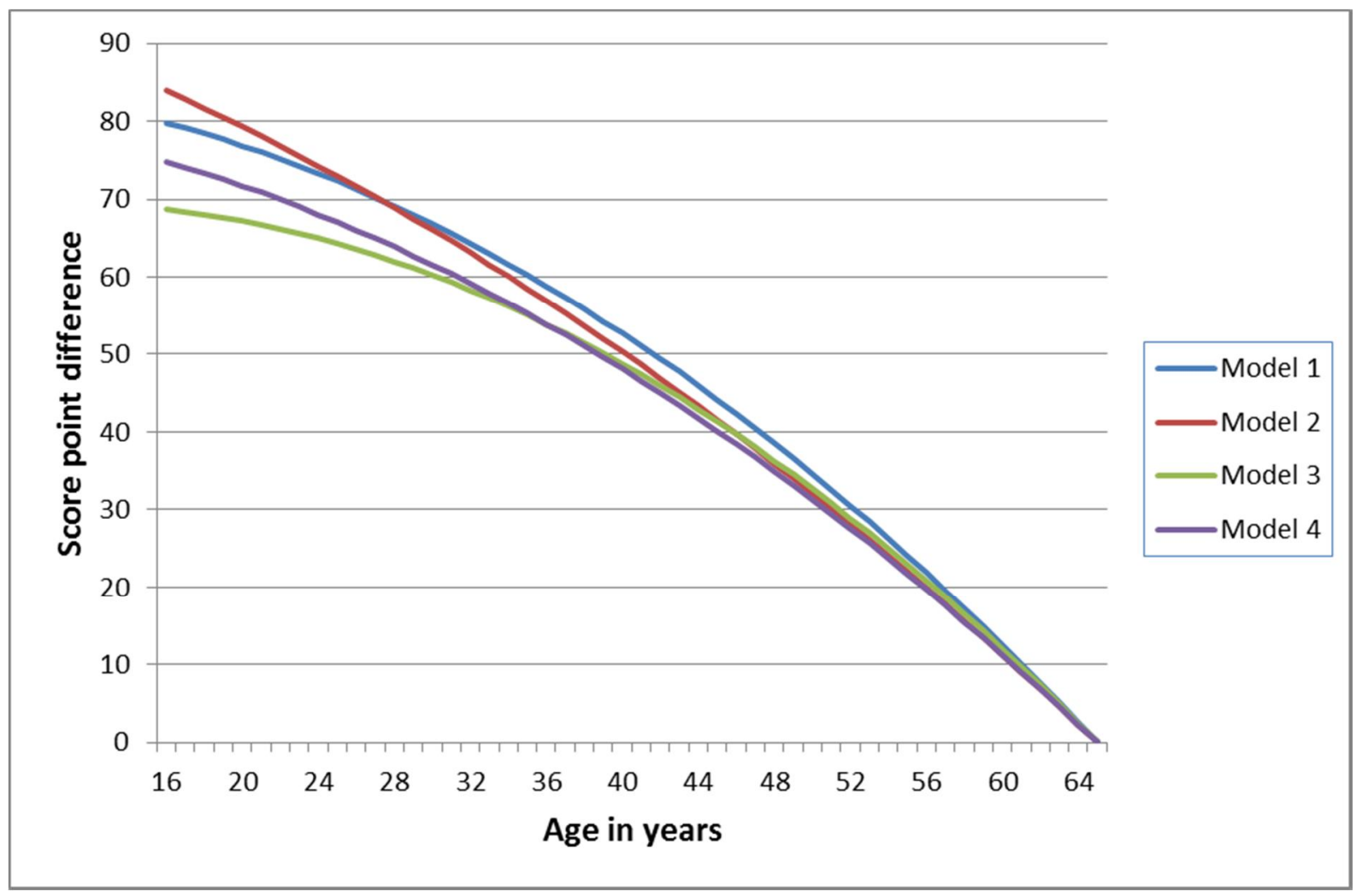

Model 2 aims to explain whether performing certain work tasks will lead adults to better problemsolving skills. In addition to the four socio-demographic factors in Model 1, Model 2 focuses on work-related learning factors (Table 4). Three factors had a statistically significant association with problem-solving, after controlling the associations with the socio-demographic factors in Model 1. The use of ICT skills at work had the strongest association with problem-solving proficiency. The active use of ICT skills is associated with higher proficiency. In more detail, the two most active ICT skills user groups have a 20-point higher performance than the group not using ICT at all. The use of numeracy skills at work was also positively associated with problem-solving skills. Adults who did not use numeracy at all at work or who belonged to the $20 \%$ most passive users were clearly below the more active user groups (9-12 points). Surprisingly, the learning at work-related factor was negatively associated with problem-solving skills. Adults learning the most at work seemed to have the lowest problem-solving proficiency. In general, this may be due to the low-level skills adults need to engage in when learning at work, as there are emerging needs for developing these abilities to manage/cope in workplace contexts. The effects of the socio-demographic factors were slightly smaller than in Model 1. Contrary to our expectations, participation in formal or non-formal adult education and training (AET) for job-related reasons in the 12 months preceding the survey or the use of reading skills at work was not statistically significantly associated with problem-solving skills, when controlling the effects of other skills used at work and socio-demographic factors in the model. This second cluster of factors related to learning at work increased the variance explained by only 1 percentage point, compared to Model 1.

Model 3 focuses on the association between everyday life learning and problem-solving skills, without variables describing the use of skills at work (Table 4). The use of ICT skills in everyday life had the strongest association with problem-solving proficiency. Again, more active use of ICT skills 
steadily improved problem-solving skills. The most active users scored 20 points higher in problemsolving than adults who did not use ICT skills in everyday life at all. The use of reading skills in everyday life was also positively associated with problem-solving skills, and the difference between passive readers (no reading at all and the least active group of readers) and more active groups of readers was 12-16 points. The use of numeracy skills in everyday life increased problem-solving proficiency in the two most active user groups. The effects of the socio-demographic factors were very close to the ones in Model 2. Participation in formal or non-format AET for non-job-related reasons in the 12 months preceding the survey had no statistically significant association with problem-solving skills when controlling the effects of other skills used in everyday life and sociodemographic variables in the model. This model explained about 4.5 percentage points more than Model 1 (only background variables).

Model 4 includes the statistically significant factors from the previous three models predicting problem-solving proficiency. Of the skills used at work, only the use of ICT skills was statistically significantly associated with problem-solving when controlling for the effects of skills use in everyday life and socio-demographic factors. Still, the two most active ICT skills user groups had 16point higher performance than the group not using ICT at all. The effect of numeracy skills use at work decreased and was no longer statistically significant, so this variable was left out of the final model. Of the skills used in everyday life, the most important variable remained the use of ICT skills. The most active users were now 15 points higher in problem-solving than adults who did not use ICT skills in everyday life. In the use of reading skills in everyday life, the difference between passive readers (no reading at all and the least active group) and the three most active groups was 9-11 points. The use of numeracy skills in everyday life increased the two most active user groups' problemsolving proficiency by $8-10$ points. The association between learning at work and problem-solving changed slightly from Model 2 (see Table 4). Adults who learned the most at work seemed to have the lowest problem-solving proficiency $(\mathrm{p}=.048)$. The pattern of the effects of the four socio-demographic factors remained the same throughout all the models, although the size of the estimates is smaller in Model 4 than in Model 1. Again, participation in continuing education at work or free time did not have a significant association with problem-solving abilities in TRE. In Model 4 socio-demographic, work-related learning and everyday life learning factors together explained $39 \%$ of the variance in problem-solving performance. The reduction in adjusted $\mathrm{R}$ squared, compared to Model 3, was due to the different number of cases in the models (Table 4).

\subsection{RQ4: The differences between adults with VET and other educational backgrounds after controlling the effects of the models}

The differences in the problem-solving proficiency of the four categories of adults based on education and age (VET versus other educational backgrounds and $\geq 40$ versus $<40$ years) are clear. Adults with educational backgrounds other than VET, who are younger than 40 years old, had the best average proficiency score, 55 points higher (i.e. more than the difference between two proficiency levels) than those in the reference group of adults with VET and age older than 40 years (Table 5, Figure 2). The next-best performing group that was 34 points above the reference group was adults with VET and who were less than 40 years of age. The difference between the younger and older groups in both educational categories was 34 points.

$* * * * * * * * * * * * *$

Insert Table 5 about here: Unadjusted (Model 0 ) and adjusted (Model 1 to 4) mean differences in problemsolving in TRE between educational and age groups 


\begin{tabular}{|c|c|c|c|c|c|c|c|c|c|c|c|c|c|c|c|}
\hline & \multicolumn{3}{|c|}{ Model 0} & \multicolumn{3}{|c|}{ Model 1} & \multicolumn{3}{|c|}{ Model 2} & \multicolumn{3}{|c|}{ Model 3} & \multicolumn{3}{|c|}{ Model 4} \\
\hline & b & $\mathrm{se}(\mathrm{b})$ & $\mathrm{p}$ & b & $\mathrm{se}(\mathrm{b})$ & $\mathrm{p}$ & b & $\mathrm{se}(\mathrm{b})$ & $\mathrm{p}$ & b & $\mathrm{se}(\mathrm{b})$ & $\mathrm{p}$ & b & $\mathrm{se}(\mathrm{b})$ & $\mathrm{p}$ \\
\hline Non-VET 16-39 years & 55.1 & 2.12 & $<0.001$ & 14.2 & 3.96 & $<0.001$ & 12.8 & 4.01 & 0.001 & 13.5 & 3.945 & 0.001 & 12.5 & 4.151 & 0.003 \\
\hline Non-VET $40-65$ years & 21.5 & 1.99 & $<0.001$ & 7.7 & 2.22 & $<0.001$ & 6.6 & 2.64 & 0.013 & 7.4 & 2.138 & 0.001 & 6.4 & 2.608 & 0.014 \\
\hline VET $16-39$ years & 33.6 & 2.44 & $<0.001$ & 4.2 & 3.68 & 0.256 & 5.6 & 3.97 & 0.162 & 5.7 & 3.599 & 0.112 & 6.4 & 3.978 & 0.108 \\
\hline VET $40-65$ years (ref.) & 0 & & & 0 & & & 0 & & & 0 & & & 0 & & \\
\hline
\end{tabular}

Note: statistically significant $p$-values in bold; n.s.=not significant

**************

$* * * * * * * * * * * * *$

Insert Figure 2 about here: Mean differences in problem-solving in TRE between groups based on education and age

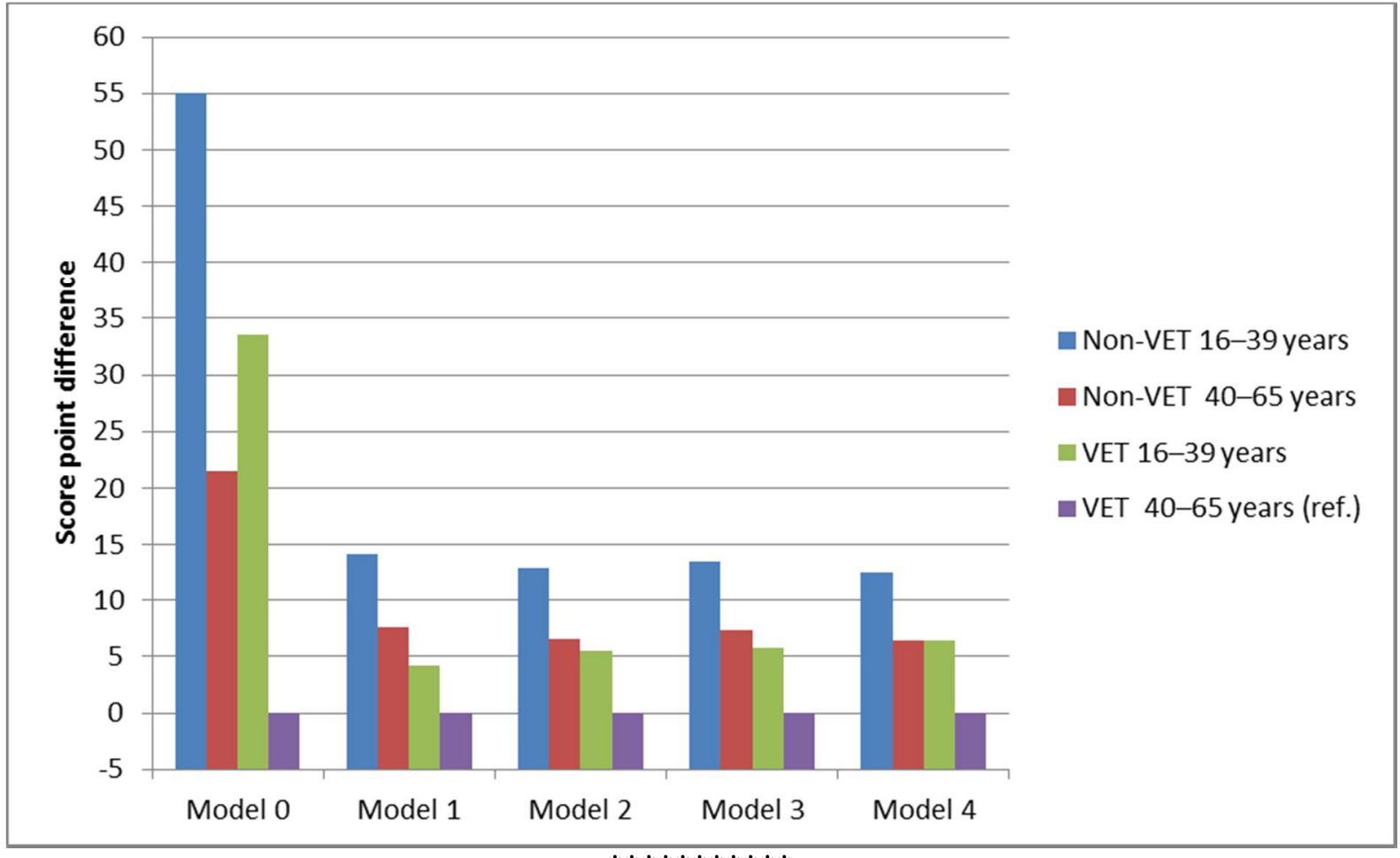

$* * * * * * * * * * * *$

The difference between the groups in problem-solving proficiency changed dramatically after controlling the effects of socio-demographic factors in Model 1 (Table 5). The best-performing group was still adults with educational backgrounds other than VET who were under 40 years old, but with only 14 points higher than the reference group $(\mathrm{p}<.001)$. The second-best performing group was adults with educational backgrounds other than VET who were over 40 years old, with 8 points higher than the reference group $(\mathrm{p}<.001)$. The difference between the two VET groups was not statistically significant $(\mathrm{p}=.256)$.

When the work and everyday life learning factors were included in the model, the additional changes between the adult groups' average problem-solving proficiency were minor (Table 5). The bestperforming group in Models 2, 3 and 4 was adults with educational backgrounds other than VET who were under 40 years old, with $12-13$ points higher than the reference group $(\mathrm{p} \leq .003)$. The differences 
for young adults with other educational backgrounds and VET adults were close to each other in size, 4-7 points. The only statistically significant difference that emerged was for old adults with educational backgrounds other than VET, since this group was larger. In sum, after controlling the effects of Models 2, 3 and 4, there were hardly any differences between adults from various age groups with VET.

\section{Conclusions}

The changing needs of workplaces create new requirements for vocational skills and professional expertise (Goos, 2013). Today, vocationally trained adults must be able to quickly take over new technologies and to solve problems in changing technological environments. This study indicates that more than two thirds of VET adults have weak skills or lack the skills in solving problems in TRE. Furthermore, when comparing adults with VET to adults with other educational backgrounds, data show that the likelihood of having fragile problem-solving skills is six times higher for adults with VET. Finally, the critical finding is that within the 16-39-year-old age group, VET adults' likelihood of being at risk is 8.5 times higher. Related to this critical finding, we found that although there is a tendency to have low problem-solving skills among adults with VET, this lower performance does not seem to be associated with VET itself. On the contrary, this study indicates that the associations between background factors and the problem-solving proficiency of adults with other educational backgrounds and VET adults are similar. Specifically, our results indicate that differences in problemsolving skills in TRE between VET and other educational backgrounds are mostly due to age, education in years, occupation and gender. After controlling the effects of these factors, the differences became considerably smaller. Therefore, it is important to stress that this study not appraise VET as the educational system, and the reason for the lower proficiency mentioned above can be found in the interrelatedness of VET with other variables. The study does however indicate that we need new ways to enhance the quality of problem-solving in TRE to respond to the needs of working life and to empower VET adults' professional development.

\section{Discussion}

The results of this study corroborate earlier findings (Hämäläinen, Cincinnato, Malin \& De Wever, 2014), indicating that when examining the similarities and differences in VET adults' problemsolving skills in TREs across 11 European countries, only a minority of VET adults perform at a high level. However, in addition to describing differences in problem-solving skills, the present study focusses also on explaining these observations. Our results bring out new knowledge for the factors that contribute to successful adults' skills. In practice, this kind of knowledge may help in developing new prospects for supporting VET adults' professional competences to meet future workplace needs. The results coincide with the notion that formal education (e.g. Billet, 2008) and workplace learning (Tynjälä, 2013) may enhance problem-solving skills in TRE. In particular, the number of years of formal education seems to have a positive association with these problem-solving skills. However, our research provides some surprising results with respect to participation in continuing education, as participation activity and problem-solving skills in TRE seem to be unrelated to each other. Instead, everyday life learning and skills used outside the workplace appear to be clearly related to problemsolving skills in TRE. Therefore, adults' skills and abilities to learn in everyday life could be more actively utilised when it comes to VET adults training and enhancing problem-solving skills in technology-rich environments. We argue that learning taking place in everyday life as well as forms of informal learning play a crucial role in empowering contemporary workplace learning. Specifically, intentional informal learning skills (referring to the ability to initiate and regulate one's own learning process, see Schulz \& Robinagel, 2010) are becoming increasingly important from the perspective of meeting 21 st century priorities. In practice, we need to develop new approaches to 
increase learning throughout one's career by predicting successful links with adults' real live problem-solving in TRE.

In this study, problem-solving skills were investigated at the personal level. However, in the future, to tackle the complex problems being faced in the workplace, abilities for networked and shared problem-solving are needed rather than solely individual skills (Hämäläinen \& Vähäsantanen, 2011). More and more often, employees participate in various problem-solving processes inside and across work organisations and professions (Billett, 2006; Noroozi et al. 2013). Thus, extensive collaboration skills are needed, as problem-solving proficiency will not only be a function of sharing knowledge, but equally of jointly building upon this shared knowledge. Therefore, VET calls for innovative learning methods to foster professional development, such as, collaborative web based e-learning (see, e.g. Inayat, Amin, Inayat, \& Salim, 2013) and reciprocal peer-tutoring (Gavota, Cattaneo, Arn, Boldrini, Motta, et al., 2010). Additionally, future work is needed to integrate the summative evaluation of individual problem-solving skills and formative assessment of collaborative knowledge construction in technology-rich environments. In addition to understanding adults' problem-solving skills in technology-rich environments, it is necessary to investigate the relation between the current state of problem-solving skills in a technology-rich environment and future societal needs in the same realm.

At their best, new technologies can provide supports for problem-solving at VET and workplace contexts, and thus address the challenges of the 21 st century. These 21 st-century work environments call for flexible, novel and customized tools to support problem solving. In practice, we need new technological solutions to make better advances of contextual and social resources through effective problem-solving and utilization of the context-aware information. However, the use of technology, such as social software for supporting problem-solving in the work context(s), in a meaningful way is still to come. Currently, the work environments are still far from supporting productive problemsolving processes and empowering work teams with technological tools. As a timely solution for this, recent research has indicated beneficial ways to support productive work practices, such as, collaborative problem-solving processes (e.g. with collaboration scripts, meaning that different kinds of research-based design principles can be used to foster specific interactions in learning and working environments, see Fischer et. al., 2013). Additionally, recent developments in the technological landscape offer a great potential to design information technologies to support VET. Currently, the innovative learning environments are increasingly developed (e.g. in the domain of logistics, see, Cuendet, Bonnard, Do-Lenh, \& Dillenbourg, 2013). In a future, the tools and environments will change; instead of mass-customized methods the emphasis will be on competence development, networking, and shared creation of content and knowledge. In line with that, recently, Tynjälä, Häkkinen, and Hämäläinen (2014) illuminated examples of how to make use of existing technologies as well as design of new technologies for empowering adults' problem-solving skills in the workplace context.

In sum, VET and workplace learning have been under pressure to change and develop their practices. The needs of the current European workplace are challenging VET adults' professional expertise. To answer these challenges, we propose three main recommendations for the future. First, VET adults' need the support and resources for professional development related to problem-solving in technology-rich work settings. Second, research-based knowledge needs to be fully applied in empowering vocational education and workplace learning to answer the changing needs of the workplaces. And third, work environments call for flexible, novel and customized tools to support problem-solving.

\section{References}


Aczel, A., Sounderpandian, J., Saravanan, P., \& Joshi, R. (2012). Complete business statistics. New Delhi: Tata McGraw Hill Education Pvt. Ltd, 7th edition.

Attwell, G. (1997). New roles for vocational education and training teachers and trainers in Europe: a new framework for their education. Journal of European Industrial Training, 21(6/7), 256-265.

Billett, S. (2006). Work, change and workers. Dordrecht: Springer.

Billett, S. (2008). Learning throughout working life: A relational interdependence between social and individual agency. British Journal of Education Studies, 55(1) 39-58.

Brand-Gruwel, S. \& Stadtler, M. (2011). Solving information-based problems: Evaluating sources and information. Learning and Instruction, 21(2), 175-179.

Braun, V., \& Clarke, V. (2006). Using thematic analysis in psychology. Qualitative Research in Psychology, 3(2), 77-101.

Cuendet, S., Bonnard, Q., Do-Lenh, S., \& Dillenbourg, P. (2013). Designing augmented reality for the classroom. Computers \& Education, 68, 557-569.

Eraut, M. (2004). Informal learning in the workplace, Studies in Continuing Education, 26(2), 247273.

Fischer, F., Kollar, I., Stegmann, K., \& Wecker, C. (2013). Toward a script theory of guidance in computer-supported collaborative learning. Educational Psychologist, 48(1), 56- 66.

Frey, C. \& Osborne, M. (2013). The future of employment: how susceptible are jobs to computerisation? Retrieved January 15, 2014 from http://www.oxfordmartin.ox.ac.uk/downloads/academic/The_Future_of_Employment.pdf

Fuller, A., \& Unwin, L. (2004). 'Expansive Learning Environments: integrating personal and organisational development', in H. Rainbird, A. Fuller and A. Munro, Eds., Workplace Learning in Context (pp. 126-144), London: Routledge.

Gavota, M., Cattaneo, A., Arn, C., Boldrini, E., Motta, E., Schneider, D. K., \& Bétrancourt, M. (2010). Computer-supported peer commenting: a promising instructional method to promote skill development in vocational education. Journal of Vocational Education \& Training, 62(4), 495-511.

Goos, M, Manning, A., \& Salomons, A. (2009). The polarization of the European labor market, American Economic Review Papers and Proceedings, 99(2).

Goos, M. (2013). How the world of work is changing: A review of the evidence. ILO Research Paper (pp. 1-54), Retrieved April 11, 2014 from http://www.econ.kuleuven.be/public/n06022/ILO20131205.pdf

Hager, P. (2001). Lifelong learning and the contribution of informal learning. In D. Aspin, J. Chapman, M. Hatton \& Y. Sawano (Eds.). International Handbook of Lifelong Learning (pp. 79-92). Dordrecht, Netherlands: Springer.

Herder, E., Koesling, A., Olmedilla, D., Hummel, H., Schoonenboom, J., Moghnieh, A., \& Vervenne, L. 2006. European lifelong competence development: Requirements and technologies for its 
realisation. Paper presented at the International Workshop in Learning Networks for Lifelong Competence Development, March 30-31, 2006, Sofia, Bulgaria. Retrieved January 15, 2014 from http://dspace.learningnetworks.org/bitstream/1820/767/1/Paper30.pdf

Hämäläinen, R., Cincinnato, S., Malin, A., \& De Wever, B. (2014). VET workers' problem-solving skills in technology-rich environments: European approach. International Journal for Research in Vocational Education and Training, 1(1), 57-80.

Hämäläinen, R., \& Vähäsantanen, K. (2011). Theoretical and pedagogical perspectives on orchestrating creativity and collaborative learning. Educational Research Review, 6(3), 169 184.

Inayat, I., Amin, R., Inayat, Z., \& Salim, S. S. (2013). Effects of collaborative web based vocational education and training (VET) on learning outcomes. Computers \& Education, 68, 153-166.

Jaimovich N., \& Siu H. (2012). The trend is the cycle: Job polarization and jobless recoveries. NBER Working Paper; 2012. Retrieved April 10, 2014 from http://www.nber.org/papers/w18334.pdf?new window=1

Levy, F. (2010). How technology changes demands for human skills. OECD Education Working Papers, No. 45, OECD Publishing. http://dx.doi.org/10.1787/5kmhds6czqzq-en

Loveder, P. (2011). Globalization and vocational education and training, In Rubenson, K. (Ed.), Adult Learning and Education (pp. 283-287), Oxford, Academia Press.

Maclean, R., \& Wilson, D. (Eds.) (2009). International Handbook of Education for the Changing World of Work: Bridging Academic and Vocational Training. Netherlands: Springer.

Noroozi, O., Biemans, H., Weinberger A., Mulder, M. \& Chizari M. (2013). Scripting for construction of a transactive memory system in multidisciplinary CSCL environments. Learning and Instruction, 25(1), 1-12.

OECD (2012). Literacy, Numeracy and Problem Solving in Technology-Rich Environments: Framework for the OECD Survey of Adult Skills. Paris: OECD Publishing. doi:10.1787/9789264128859-en

OECD, (2013a). OECD Skills Outlook 2013: First Results from the Survey of Adult Skills. Paris: OECD Publishing. doi: http://dx.doi.org/10.1787/9789264204256-en

OECD. (2013b). Technical Report of the Survey of Adult Skills (PIAAC). Retrieved April 11, 2014 from http: http://www.oecd.org/site/piaac/_Technical\%20Report_17OCT13.pdf

Peers, I. (1996). Statistical analysis for education and psychology researchers. London: Falmer Press.

Schulz, M., \& Stamov Roßnagel, C. (2010). Informal workplace learning: an exploration of age differences in learning competence, Learning and Instruction, 20(5), 383-99.

Stenström, M-L., \& Tynjälä, P. (2009). Introduction. In M-L. Stenström \& P. Tynjälä (eds.) Towards integration of work and learning. Strategies for connectivity and transformation. Springer (pp. $3-10)$. 
Taloussanomat, (2014, January 4). Suomesta on kadonnut 120 työpaikkaa päivässä. Retrieved April 11, 2014 from http://www.taloussanomat.fi/tyomarkkinat/2014/01/04/suomesta-on-kadonnut120-tyopaikkaa-paivassa/201435/12

Teichler, U. (2007). Does higher education matter? Lessons from a comparative graduate survey, European Journal of Education, 42(1), 11-34.

Tuomi-Gröhn, T., \& Engeström, Y. (Eds.). (2003). Tuomi-Gröhn, T., \& Engeström, Y. (Eds.). (2003). Between school and work: New perspectives on transfer and boundary-crossing. Amsterdam: Pergamon.

Tynjälä, P. (2013). Toward a 3-P model of workplace learning: a literature review. Vocations and Learning. Studies in Vocational and Professional Education, 6(1), 11-36.

Tynjälä, P., Häkkinen, P. \& Hämäläinen R., (2014, iFirst). TEL@ work - towards integration of theory and practice. British Journal of Educational Technology. http://onlinelibrary.wiley.com/doi/10.1111/bjet.12164/pdf

Virolainen, M., \& Stenström, M.-L. (2013). Building workplace learning with polytechnics in Finland: multiple goals and cooperation in enhancing connectivity. Journal of Education and Work, 26(4), 376-401. http://dx.doi.org/10.1080/13639080.2012.661846.

Appendices

$* * * * * * * * * * * *$

Insert Table A1 about here: Distribution (in \%) of proficiency in problem-solving in TRE by educational background: population, 16-39-year olds, and 40-65-year olds

\begin{tabular}{|c|c|c|c|c|c|c|c|c|c|}
\hline & \multicolumn{3}{|c|}{ POPULATION } & \multicolumn{3}{|c|}{ 16-39 YEARS } & \multicolumn{3}{|c|}{ 40-65 YEARS } \\
\hline & \multirow[t]{3}{*}{ VET } & \multicolumn{2}{|c|}{ NON-VET } & \multirow[t]{3}{*}{ VET } & \multicolumn{2}{|c|}{ NON-VET } & \multirow[t]{3}{*}{ VET } & \multicolumn{2}{|c|}{ NON-VET } \\
\hline & & Low & Up. & & Low & Up. & & Low & Up. \\
\hline & & Sec. & Sec. & & Sec. & Sec. & & Sec. & Sec. \\
\hline Not classified & 25.5 & 34.6 & 7.1 & 7.1 & 9.5 & 3.2 & 36.8 & 58.5 & 10.8 \\
\hline At risk & 16.4 & 13.1 & 6.4 & 8.0 & 5.4 & 1.6 & 21.5 & 20.5 & 11.0 \\
\hline Weak & 33.1 & 26.0 & 27.1 & 37.2 & 35.3 & 16.6 & 30.6 & 17.1 & 37.1 \\
\hline Moderate & 22.2 & 23.2 & 45.0 & 41.5 & 43.6 & 54.8 & 10.4 & 3.7 & 35.7 \\
\hline Strong & 2.8 & 3.2 & 14.4 & 6.2 & 6.2 & 23.8 & 0.7 & 0.3 & 5.4 \\
\hline Total & 100 & 100 & 100 & 100 & 100 & 100 & 100 & 100 & 100 \\
\hline $\mathbf{N}$ & 1750 & 978 & 2736 & 651 & 477 & 1291 & 1099 & 501 & 1445 \\
\hline
\end{tabular}

Note: Low Sec. =lower secondary or less (ISCED 1, 2, 3C (short)); Up. Sec. =upper secondary or more (ISCED 3 A-B-C(long), 5 A-B, 6).

$* * * * * * * * * * * *$

\section{Acknowledgments}

This research was supported by the Academy of Finland (Project 258659). 